\title{
Resolution of liaison for lexical access in French
}

\author{
Elsa Spinelli, Anne Cutler and James M. McQueen \\ Max Planck Institute for Psycholinguistics, Nijmegen
}

\begin{abstract}
Spoken word recognition involves automatic activation of lexical candidates compatible with the perceived input. In running speech, words abut one another without intervening gaps, and syllable boundaries can mismatch with word boundaries. For instance, liaison in 'petit agneau' creates a syllable beginning with a consonant although 'agneau' begins with a vowel. In two cross-modal priming experiments we investigate how French listeners recognise words in liaison environments. These results suggest that the resolution of liaison in part depends on acoustic cues which distinguish liaison from non-liaison consonants, and in part on the availability of lexical support for a liaison interpretation.
\end{abstract}

Résumé : La reconnaissance de la parole implique l'activation automatique des 'candidats lexicaux' compatibles avec l'entrée perceptuelle. Dans le flux sonore les mots s'enchaînent sans interruption, et les limites de syllabes peuvent se confondre avec celles de mots. Ainsi, dans 'petit agneau' la liaison crée une syllabe qui commence par une consonne alors que le mot 'agneau' commence par une voyelle. Dans deux expériences où les temps de réaction étaient mesurés, on s'est demandé comment des locuteurs français reconnaissaient des mots dans des contextes de liaison. Les résultats permettent de penser que la résolution de la liaison dépend d'une part de signaux acoustiques permettant de distinguer entre les consonnes de liaison et celles de non-liaison, mais d'autre part de la disponibilité du support lexical pour une interprétation de liaison.

To recognize spoken words, listeners must match the sound patterns of speech to specific lexical representations. In contrast to written language where words are separated by blank spaces, there are no clear word boundaries in spoken language. This means that a given stretch of speech can be consistent with multiple lexical hypotheses, and that these hypotheses can begin at different points in the input. The most common view of spoken word recognition is that the listener considers the lexical candidates that are consistent with the perceptual input in parallel; in models such as TRACE (McClelland \& Elman, 1986) and Shortlist (Norris, 1994), for example, candidate words are activated simultaneously, and compete with one another. Processing the speech stream can therefore give rise to transient ambiguities. Thus in son chat potelé, his plump cat, the recognition system must select between competing hypotheses (chapeau versus chat po...) which, to a first approximation, are supported equally by acoustic information. Similarly, the system must also avoid segmenting the signal in cases where trusting an apparent word boundary would 
lead to incorrect lexical hypotheses. Such situations are common with embedded words (e.g. marre, pond, and motte, clod, in marmotte, marmot). However, despite the continuity of the speech signal, listeners manage to isolate words in the speech chain and are rarely misled.

To this end, listeners exploit a number of cues available in the input. Off-line studies have shown that listeners can identify the correct segmentation of ambiguous two-word utterances. Nakatani and Dukes (1977) examined English phrases such as buy zinc / buys ink, and found that there were acoustic cues for junctures at the beginning and occasionally at the end of words - glottal stops, laryngealization, aspiration on voiceless stops. Quené (1992), with a forced choice task, showed that listeners can exploit durational cues to detect word boundaries in pairs of Dutch words like diep in / die pin. Dumay, Content and Frauenfelder (1999) examined whether such cues can be used for on-line segmentation. With a word-spotting task, they showed that subjects detected the French word tante more rapidly in the nonword tantrou when tantrou was extracted from the sentence tante roublarde (CVC-CV...), in which the duration of the pre-boundary vowel and the liquid is greater, than when it was extracted from temps troublant (CV-CCV...). This suggests that the sequence $/ \mathrm{tr} /$ is different when produced during resyllabification and when produced within a syllable (see also Fougeron, 2001).

Another source of information comes from language-specific metrical structure. In English, most content words start with a strong syllable. Cutler and Norris (1988) proposed the Metrical Segmentation Strategy according to which listeners exploit these prosodic probabilities to segment speech. Lexical access would be initiated at each strong syllable which the listener encounters. In a word-spotting experiment, Cutler and Norris showed that CVCC words like mint are easier to detect in Strong-Weak sequences (e.g., [mint'S]than in Strong-Strong sequences (e.g., [mint'iS]. In the latter sequences, detection suffered from misalignment with the segmentation boundary before the second strong syllable.

In French, the basis of rhythmic structure is the syllable. Because French has a clear syllabic structure, the syllable has been referred to as the functional unit either of classification (Mehler, Dommergues, Frauenfelder \& Segui, 1981; Segui, Dupoux \& Mehler, 1990; Segui, Frauenfelder \& Mehler, 1981) or of segmentation (Dumay, Frauenfelder \& Content, 2002). Just as English listeners take advantage of the metrical structure of their language, French listeners could rely on the regularities of the syllabic structure of French to segment speech. The Syllable Onset Segmentation Hypothesis (SOSH, Dumay et al., 2002) rests on the assumption that word boundaries often coincide with syllable boundaries and postulates that syllable onsets constitute potential alignment points for lexical access. In a word-spotting task, Dumay et al. (2002) showed that detecting lac, lake, is easier in the nonword zunlac (syllabified zun.lac) than in the nonword zuglac (zu.glac). As in the mintayf case of Cutler and Norris (1988), the recognition of $l a c$ suffers from misalignment with the segmentation boundary before the $/ \mathrm{g} /$ in zuglac.

Norris, McQueen, Cutler and Butterfield (1997) proposed a segmentation strategy based on the idea that the input should be segmented in order to produce possible words. The Possible Word Constraint (PWC) uses silence, metrical and phonotactic information as cues for the marking of likely word boundary locations and works by decreasing the activation of candidate words that are misaligned with these possible boundaries. In French, the PWC would put possible word boundary markers at the onset of syllables and 
decrease the activation of lexical candidates that are misaligned with these syllable onsets. In that respect, the PWC predicts a penalty in the recognition of words misaligned with syllable boundaries and thus accounts for the Dumay et al. (2002) results in a way which is very similar to that offered by the SOSH.

However, resyllabification across word boundaries occurs very often in normal conversation in French. Resyllabification results from several phonological processes that occur in connected speech. Elision refers to the dropping of phonemes (e.g., le, the, and indien, indian, will give rise to l'indien [resyllabified lin.dien]). Another case of cross-word resyllabification comes from Enchainment, which occurs when a word containing a final consonant that is always realized (e.g. the $/ \mathrm{k} /$ of chaque, each) is followed by a vowelinitial word. For instance, avion, plane, will lead to the syllabification cha.ka.vion. A case of great interest comes from Liaison, which consists of two processes: the surfacing of a latent segment, and resyllabification (Encrevé, 1988). When a French speaker says the word petit (small), for example, the final [t] will not be produced if the next word begins with a consonant (e.g., petit chat, small cat), but will be produced if the next word begins with a vowel (e.g., petit avion, small plane). Furthermore, when the [t] is produced, it appears in the initial position of the first syllable of the following word. In the worst case, liaison can generate another word (such as tamis, net, in petit ami, small friend). Liaison produces a tricky situation for French listeners. Although liaison might have little effect on the recognition of the first word, it would appear to make recognition of the second word more difficult, since it makes vowel-initial words seemingly consonant-initial.

The pervasiveness of resyllabification in French implies that the word recognition system has to be able to deal with situations in which syllabic boundaries do not coincide with word boundaries. In the case of liaison, it also has to deal with the surfacing of a latent segment, a segment that is not produced when the word is produced in isolation. A segmentation strategy based on alignment of candidate words with the onsets of syllables such as SOSH or PWC might therefore mislead French listeners each time resyllabification occurs. Gaskell, Spinelli \& Meunier (in press) addressed how listeners process resyllabification due to enchainment and liaison, and whether there is a cost in processing resyllabified words. They showed in a cross-modal repetition priming study that the recognition of a target word is not impaired in any manner by resyllabification phenomena due to liaison and enchainment. For instance, the visual target ITALIEN (Italian) was recognized equally fast in a liaison utterance (un genereux italien, a generous Italian), an enchainment utterance (un virtuose italien, an Italian virtuoso) and in a non-resyllabified utterance (un chapeau italien, an Italian hat). These results suggest that information other than syllabic boundaries might be relevant in the segmentation process. Plausible additional factors are acoustic cues, the influence of lexical context and/or statistical information regarding the transitions between phonemes.

The current study explores how, in the case of liaison, the resyllabification problem is solved. It focuses on the role of lexical and acoustic factors. Experiment 1 used the crossmodal repetition priming task to examine whether lexical context is used by listeners to resolve transient ambiguities due to liaison. We tried to determine whether the segmentation process is influenced by whether or not the resyllabifying liaison consonant can be attached to the preceding word. We compared performance in a condition in which a liaison consonant appeared in a liaison context (e.g., the final /t/ of petit, in the phrase petit agneau, little lamb), with a condition in which it appeared in a context where liaison is impossible (demi-t-agneau, half-t-lamb). In Experiment 2, we examined whether acoustic cues could signal liaison. We used prime sentences that were cross-spliced tokens of these 
two conditions. Acoustic measurements were carried out to determine the nature of these cues.

\section{Experiment 1}

The goal of Experiment 1 was to examine whether lexical information plays a role in resolving transient ambiguities due to liaison. Our hypothesis was that lexical information is used to interpret the resyllabified (liaison) consonant as part of the preceding word. Thus, we expected vowel-initial candidates like agneau to be easier to recognize in a situation where the lexical context supports the attachment of the resyllabified consonant to the preceding word (e.g., petit agneau) than in a situation where the lexical context does not allow the medial consonant to be assigned to the preceding word (e.g., demi tagneau).

We contrasted these two conditions with an enchainment condition, in which the medial, resyllabified consonant was one which is always realized (e.g., the /t/ of mérite, merit, in mérite agneau). On the simplest account, one would predict that agneau would be easier to recognize in this context than in either of the other two, since in only this condition is the / $\mathrm{t} /$ unambiguously part of the lexical representation of the preceding word (mérite). Our prediction, however, was that if the lexicon could also be used to resolve the liaison case (i.e., if the / $\mathrm{t} /$ in petit agneau could be assigned to petit), then agneau ought to be easier to recognize in both the liaison and enchainment conditions than in the illegal liaison condition (demi t agneau).

\section{Method and Participants}

Forty students of the University René Descartes, Paris V, were paid for their participation. They were all native speakers of French, had normal or corrected vision and reported no hearing impairment.

\section{Stimuli and Design}

Thirty-two words beginning with a vowel were selected from a French database, (Trésor de la Langue Française, TLF, Imbs, 1971) and served as experimental targets (e.g., agneau). Four two-word phrases were associated with each target and served as primes. One corresponded to a condition of legal liaison (petit agneau), another one corresponded to a condition of illegal liaison (demi t agneau). The illegal liaison condition was obtained by creating a phonological violation due to an additional consonant (e.g. /t/) after the preceding word. The third phrase corresponded to a condition of enchainment (mérite agneau). Both the enchainment and illegal liaison contexts were meaningless and syntactically incorrect phrases while the legal liaison condition was meaningful.

The last prime was not related to the target and served as baseline (diabète oiseau, diabetes bird, also meaningless). The mean target frequency was 93 occurrences per million (frequencies per million, given by TLF). In the legal liaison set, the mean frequency of the first word of the sentence prime (e.g. petit) was 884 occurrences per million, in the illegal liaison set, 938 occurrences per million and in the enchainment condition, 73 
occurrences per million. In the baseline condition, the first and second word mean frequencies were 10 and 81 occurrences per million ${ }^{1}$.

Thirty two vowel-initial pseudowords were also created (e.g., anaint). Four prime phrases were associated to each of them. One corresponded to a condition of legal liaison (petit anneau, little ring), another corresponded to a condition of illegal liaison (demi $t$ anneau, half $\mathrm{t}$ ring), a third corresponded to a enchainment condition (mérite anneau, merit ring) and a last one was not related to the target and served as baseline (diabète ignare, diabetes ignorant). Because there are a limited number of adjectives like demi which do not support liaison, the first words of the prime phrases were repeated across all conditions. Examples of word and pseudoword targets with the four associated priming conditions are shown in Table $1^{2}$.

In order to reduce the proportion of related pairs to $21 \%, 160$ targets ( 80 words, 80 pseudowords) were presented in non-related conditions. Sixty-four of them were preceded by a "potential liaison phrase" in which the first word contained a final liaison consonant but the following word began with this consonant (e.g., charmant tango - oignon; lovely tango - onion). Overall, there were equal number of targets beginning with vowels and consonants.

\section{Procedure}

The prime phrases were recorded in a sound-attenuated booth by a female native speaker of French on a Digital Audio Tape (DAT). The illegal liaison phrases (demi t agneau) were pronounced as if the added consonant was in word-initial position (the speaker intended demi tagneau rather than demit agneau). Items were then digitized at a sampling rate of 22 $\mathrm{kHz}$ with 16-bit analog-to-digital conversion using the Xwaves speech editor. The phrases were transferred to the left channel of the DAT. Square wave clicks appeared on the right channel of the DAT and were time-locked with the onset of the prime phrases, as determined by visual inspection of the waveforms. The duration of each word and phrase was measured and the visual targets were displayed with a delay from phrase onset, such that they appeared half way through the second word of the prime phrase.

Participants were tested individually in a quiet room. Primes was presented auditorily at a comfortable sound level through headphones. Targets were displayed visually in lower case at the center of a computer screen. The participants were informed that each visual target could be either a word or a pseudoword, and were asked to perform lexical decision on each target by pressing as quickly and as accurately as possible one of two response buttons. They were required to press the yes button with the forefinger of their preferred hand and the no button with the forefinger of their other hand. The computer clock was triggered at the presentation of the target on the screen and stopped when the subject responded. Response latencies and errors were collected. The stimuli were counterbalanced across four experimental lists so that each participant received all priming conditions (legal liaison, illegal liaison, enchainment and baseline) but saw each target only once. The order

\footnotetext{
1 As the first words of the prime phrases were not matched in frequency across the 4 conditions, correlations between response times and the frequency of the first word of the prime phrase were carried out within each condition. None of the correlations were significant (legal liaison, $r=0.06, \mathrm{~ns}$, illegal liaison, $r=0.3$, $n s$, enchainment, $r=-0.17$, $n s$, baseline, $r=0.03$, $n s$ ).

2 See <http://www.mpi.nl/world/persons/private/anne/materials.html $>$ for a full list of the experimental materials.
} 
of stimulus presentation was pseudo-randomized and the position of the targets was kept constant across the lists. The duration of the session was approximately twenty minutes.

Table 1: Examples of Word and Pseudoword Targets in the 4 Priming Conditions of Experiment 1.

\begin{tabular}{|c|c|c|c|c|}
\hline & Legal liaison & Illegal Liaison & Enchainment & Baseline \\
\hline \multicolumn{5}{|l|}{ Targets } \\
\hline $\begin{array}{l}\text { Word } \\
\text { agneau }\end{array}$ & petit agneau & demi t agneau & mérite agneau & diabète oiseau \\
\hline $\begin{array}{l}\text { Pseudoword } \\
\text { anaint }\end{array}$ & petit anneau & demi t anneau & mérite anneau & diabète ignare \\
\hline
\end{tabular}

\section{Results}

Reaction times were calculated from visual target presentation to response onset. Reaction times longer than $1000 \mathrm{~ms}(0.9 \%)$ were removed. Errors were removed excluding $1.9 \%$ of responses. Mean RTs and error rates are given in Table 2. The results were evaluated using one-way repeated measure Analyses of Variance (ANOVAs) with 4 levels of condition (legal liaison, illegal liaison, enchainment and baseline). F values are reported for analysis with subjects as repeated measure (F1) and with items as repeated measure (F2).

Table 2: Mean Reaction Times (RT, in Milliseconds), Standard Deviation for Correct Responses to the Word Targets (SD), and Percentage of Errors in the 4 Priming Conditions of Experiment 1.

\begin{tabular}{|c|c|c|c|c|}
\hline & Legal Liaison & Illegal Liaison & Enchainment & Baseline \\
\hline RT & 514 & 529 & 531 & 557 \\
\hline SD & (59) & $(66)$ & (67) & $(61)$ \\
\hline Errors & $1.25 \%$ & $1.9 \%$ & $2.5 \%$ & $2.1 \%$ \\
\hline
\end{tabular}

The analyses revealed a significant main effect of priming condition $(\mathrm{F} 1(3,117)=11.98$, $\underline{\mathrm{p}}<.001 ; \mathrm{F} 2(3,93)=11.60, \underline{\mathrm{p}}<.001)$. Planned comparisons showed a significant facilitatory effect for each repetition condition versus the baseline condition $(F 1(1,39)=30.39$, $\mathrm{p}<.001$; $\mathrm{F} 2(1,31)=22.80, \mathrm{p}<.001$ for legal liaison versus baseline; $\mathrm{F} 1(1,39)=14.83, \underline{\mathrm{p}}<.001$; $\mathrm{F} 2(1,31)=16.37, \underline{\mathrm{p}}<.001$ for illegal liaison versus baseline; and $\mathrm{F} 1(1,39)=11.06, \underline{\mathrm{p}}<.002$; $\mathrm{F} 2(1,31)=12.67, \underline{\mathrm{p}}<.002$ for enchainment versus baseline). Moreover, responses in the legal liaison condition were faster than those in the illegal liaison condition $(\mathrm{F} 1(1,39)=$ 
4.36, $\mathrm{p}<.04 ; \mathrm{F} 2(1,31)=3.98, \underline{\mathrm{p}}=.05)$, and faster than those in the enchainment condition $(\mathrm{F} 1(1,39)=7.17, \underline{\mathrm{p}}<.01 ; \mathrm{F} 2(1,31)=5.65, \underline{\mathrm{p}}<.02)$. The enchainment condition did not differ from the illegal liaison condition $(\mathrm{F} 1(1,39)<1 ; \mathrm{F} 2(1,31)<1)$. Analyses conducted on errors revealed no effect of priming condition $(\mathrm{F} 1(3,117)<1 ; \mathrm{F} 2(3,93)<1)$.

\section{Discussion}

We observed a repetition effect for the three related conditions and among them, a difference between the legal and illegal liaison conditions. As predicted, agneau was easier to recognize after hearing a phrase with legal liaison (petit agneau in which petit has an underlying liaison $/ \mathrm{t} /$ for liaison) than after hearing a phrase with illegal liaison (demi $t$ agneau in which demi has no underlying / $t$ / for liaison). These results suggest that when the lexical context supports the attachment of the resyllabified consonant to the preceding word, the recognition of a vowel-initial lexical candidate (e.g., agneau) is not impaired. On the other hand, such candidates are more difficult to recognize when the lexical context makes it impossible to assign the critical consonant to the preceding word (e.g., in demi $t$ agneau).

One surprising result, however, was the finding that responses in the enchainment condition were slower than in the liaison condition. We had predicted that responses in the liaison condition would be as fast as those in the enchainment condition, or, if there was no lexical support for liaison consonants, slower than those in the enchainment condition. It is possible that responses were slower in the enchainment and illegal liaison conditions because the phrases in these two conditions were meaningless, in contrast to those in the liaison condition. We will return to this issue below. Note, for the moment, that the incorrectness induced by the phonological violation of illegal liaison (demi t agneau) and that induced by the syntactic-semantic violation in the enchainment condition (mérite agneau) are not strictly comparable. In the latter case, although the lexical context should not impair segmentation of agneau (since the word mérite supports the consonant), the slower response times could reflect a difficulty in higher-level processing such as syntactic or semantic integration.

The results of Experiment 1 show that in a liaison environment, listeners are capable of using lexical context, early in processing, to attach the liaison consonant to the preceding word in order to achieve a lexical segmentation of the phrase. Listeners use the fact that petit has an underlying / $\mathrm{t}$ / for liaison to attach the surfacing consonant to petit, and are thus able to consider lexical hypotheses with initial vowels, such as agneau.

In addition to this lexical effect, it could be that there are also acoustic cues which could signal liaison. Because phonemes can have different acoustic-phonetic properties depending on the context in which they are produced, we could hypothesize that a liaison phoneme such as the final $[\mathrm{t}]$ in petit agneau would be acoustically different from an initial phoneme such as the initial [ $\mathrm{t}$ ] in petit tableau (or, as in the illegal liaison condition, demi $t$ agneau). Hence, the different allophonic realizations of the $[\mathrm{t}]$ might be used to disambiguate the liaison situation. In a discrimination task, Yersin-Besson and Grosjean (1996) showed that utterances like son oeuf / son neuf (his egg / his nine) were fully ambiguous and the duration ratio of the $/ \mathrm{n} /$ liaison phoneme and $/ \mathrm{n} /$ initial phoneme was close to 1, which suggested that there is no acoustic marking of liaison. However, Wauquier-Gravelines (1994) showed that listeners find it harder to detect a liaison phoneme (e.g., /t/ in grand éléphant, big elephant, in which grand has an underlying /t/ for liaison) than an initial phoneme (e.g., grand téléphone, big telephone) which suggests that 
listeners could somehow be sensitive to the distinction between liaison and initial phonemes. Moreover, Dejean de la Batie (1993) asked non-native listeners to determine whether a nonword began with a consonant or a vowel (e.g., tirbois / irbois). She found that the proportion of / $\mathrm{t}$--initial responses were higher when subjects heard $/ \mathrm{t} /$-initial items (e.g., c'est un grand tirbois) than when they heard vowel-initial items (e.g., c'est un grand irbois), suggesting that there were some perceptible differences between the two utterances. The acoustic measurements of the stimuli revealed a longer VOT and closure duration in initial /t/ cases (e.g., grand tirbois) than in liaison resyllabified /t/ cases (e.g., grand irbois), suggesting again that word-initial consonants are perceptually distinguishable from liaison consonants.

Spinelli, McQueen and Cutler (in press) recently examined how lexical ambiguities in liaison contexts are processed. The activation pattern of two competing candidates in

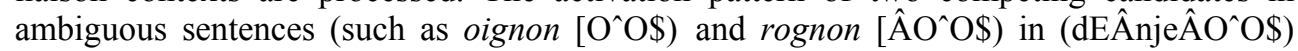
was examined as a function of the speaker's intention to produce the vowel-or consonantinitial candidate. Although unintended words in such ambiguous phrases (e.g., oignon in dernier rognon and rognon in dernier oignon) were weakly activated, the results showed that there were subtle but reliable durational differences between the two versions of the lexically ambiguous phrases and that these cues to word juncture guided listeners' segmentation.

Experiment 2 was thus designed to determine whether such acoustic cues could account for the effect found in Experiment 1. For this purpose, we created hybrid phrases from the legal and illegal liaison conditions of Experiment 1 by cross-splicing the segments corresponding to the liaison consonant (or added consonant) plus the following word, for example, /tanyo/ in petit agneau and demi t agneau. If acoustic cues can signal liaison, these hybrid phrases thus contain conflicting information. For instance, in the cross-spliced phrase petit agneau, the lexical context supports vowel-initial candidates (e.g., agneau), but the acoustic information would favor consonant-initial candidates (i.e., words beginning ta...). Such conflicting cues should tend to reduce the difference observed between the legal and illegal liaison conditions in Experiment 1.

\section{Experiment 2}

\section{Method and Participants}

Forty native speakers of French were paid for their participation. None reported hearing or visual impairments and none had participated in Experiment 1.

\section{Stimuli and Design}

The 32 experimental target words from Experiment 1 were used as targets (e.g., agneau). Four prime phrases were paired with each target. Two prime phrases were the conditions of legal liaison (petit agneau) and illegal liaison (demi t agneau) from Experiment 1 . The other two were cross-spliced tokens of those conditions (legal liaison: petit agneau*; illegal liaison: demi t agneau*). The latter two conditions were obtained by cross-splicing the segments corresponding to the liaison consonant (or added consonant) plus the following word (e.g., /tanyo/ in petit agneau and demi t agneau). Splices were made by visual and auditory examination of waveforms and spectrograms, such that clicking noises were avoided (at onset of closure for the stop consonants $/ \mathrm{t} /$ and $/ \mathrm{p} /$, at the end of second and third formants of the preceding vowel for the fricative $/ \mathrm{z} /$ and the liquid $/ \mathrm{r} /$ ). 
The 32 experimental pseudoword targets from Experiment 1 were also re-used. Four prime phrases were associated to each of them. Two prime phrases were the conditions of legal liaison (petit anneau) and illegal liaison (demi t anneau) from Experiment 1; and two other prime phrases were cross-spliced tokens of this two conditions (legal liaison: petit anneau*; illegal liaison: demi $\boldsymbol{t}$ anneau*). The stimuli were counterbalanced across four experimental lists so that each participant received all four conditions, but saw each target only once. The experimental lists also contained 224 unrelated filler pairs (112 with word and 112 with pseudoword targets) so that the proportion of related pairs was $22 \%$. The task and stimulus presentation procedures were identical to those of Experiment 1.

\section{Results and Discussion}

Reaction times were calculated from target presentation to response onset. Reaction times longer than $1000 \mathrm{~ms}(0.6 \%)$ were removed. Errors were removed excluding $1.2 \%$ of responses. One subject was removed due to a high proportion of errors (41\%). Mean RTs and error rates are given in Table 3.

Table 3: Mean Reaction Times (RT, in Milliseconds), Standard Deviation for Correct Responses to the Word Targets (SD), and Percentage of Errors in the 4 Priming Conditions of Experiment 2.

\begin{tabular}{|c|c|c|c|c|}
\hline & \multicolumn{2}{|c|}{ Natural stimuli } & \multicolumn{2}{|c|}{ Cross-spliced stimuli } \\
\hline & Legal Liaison & Illegal Liaison & Legal Liaison* & Illegal Liaison* \\
\hline$R T s$ & 511 & 538 & 517 & 528 \\
\hline$S D$ & (70) & (69) & $(59)$ & (64) \\
\hline Errors & $1.28 \%$ & $1.28 \%$ & $0.6 \%$ & $1.6 \%$ \\
\hline
\end{tabular}

Two-way ANOVAs with legality (legal liaison, illegal liaison) and stimulus type condition (natural, cross-spliced) were performed on the data. ANOVAs conducted on RTs revealed that responses were faster in the legal than in the illegal liaison conditions $(\mathrm{F} 1(1,38)=$ $15.28, \underline{\mathrm{p}}<.001 ; \mathrm{F} 2(1,31)=9.48, \underline{\mathrm{p}}<.004)$. No main effect of stimulus type was found (F1( 1 , $38)<1$; F $2(1,31)<1)$ but the legality $\mathrm{x}$ stimulus type interaction was significant by subjects but not by items $(\mathrm{F} 1(1,38)=4.11, \mathrm{p}<.05 ; \mathrm{F} 2(1,31)=1.38$, ns). Planned comparisons assessed the legality effect under the natural and cross-spliced conditions. For the natural utterances, responses were significantly faster in the legal than in the illegal condition $(\mathrm{F} 1(1,38)=14.21, \underline{\mathrm{p}}<.001 ; \mathrm{F} 2(1,31)=8.00, \underline{\mathrm{p}}<.005)$. For the cross-spliced stimuli, the equivalent legality effect was significant only by subjects $(F 1(1,38)=3.98, \underline{p}<.05 ; \mathrm{F} 2(1,31)$ $=1.78$, ns). Analyses conducted on errors revealed no effect of legality, no effect of stimulus type and no interaction between these two factors (all Fs $<1$ ).

In this experiment, the legality effect observed in Experiment 1 was replicated. However, this effect was reduced when the tagneau's from petit agneau and demi tagneau were cross-spliced. Moreover, the response times were not slowed down for the crossspliced stimuli. The reduction of the effect for the cross-spliced stimuli suggests that the 
resolution of liaison depends not only on the availability of lexical hypotheses to which liaison consonants can be attached but also on acoustic cues which signal liaison ${ }^{3}$.

Given that listeners can apparently exploit acoustic information to segment the input correctly in liaison environments, we attempted to determine the nature of those acoustic cues. Durational measurements were conducted on the legal liaison, illegal liaison and enchainment stimuli. Segment durations for the surfacing consonant (C) and for the vowels preceding $\left(\mathrm{V}_{1}\right)^{4}$ and following $\left(\mathrm{V}_{2}\right)$ the consonant were measured from waveforms and spectrograms. Vowel durations were measured from the onset of the second and third formants to the offset of the second and third formants. Consonant durations were measured from the offset of the preceding vowel to the onset of the following vowel.

Table 4: Mean Segmental Durations (in Milliseconds) and Standard Deviation (SD) for the Surfacing Consonant $(C)$, the Preceding Vowel $\left(V_{1}\right)$ and the Following Vowel $\left(V_{2}\right)$ in the Context of Legal Liaison, Illegal Liaison and Enchainment.

\begin{tabular}{|l|c|c|c|c|}
\hline & $V_{1}$ & $C$ & $V_{2}$ & $\begin{array}{c}\text { Total } \\
\left(V_{f}+C+V_{2}\right)\end{array}$ \\
\hline Legal Liaison & 96 & 70 & 103 & 268 \\
\hline$S D$ & $(22)$ & $(21)$ & $(24)$ & $(33)$ \\
\hline Illegal Liaison & 85 & 82 & 98 & 265 \\
\hline SD & $(17)$ & $(19)$ & $(29)$ & $(29)$ \\
\hline Enchainment & 102 & 75 & 99 & 276 \\
\hline SD & $(25)$ & $(24)$ & $(22)$ & $(31)$ \\
\hline
\end{tabular}

One-way ANOVAs were conducted on these data with context (legal liaison, illegal liaison and enchainment) as the main factor. The analyses first revealed that although there was a main effect of context for the total duration of $\mathrm{V}_{1}+\mathrm{C}+\mathrm{V}_{2}(\mathrm{~F}(2,54)=5.3, \underline{\mathrm{p}}<.008)$, the total duration of $\mathrm{V}_{1}+\mathrm{C}+\mathrm{V}_{2}$ in the liaison context did not differ from the total duration of $\mathrm{V}_{1}+\mathrm{C}+\mathrm{V}_{2}$ in the illegal liaison context $(\mathrm{F}(1,27)=1.3$, ns) nor from the total duration of $\mathrm{V}_{1}+\mathrm{C}+\mathrm{V}_{2}$ in the enchainment context $(\mathrm{F}(1,27)=3.3$, ns $)$. There was a significant context effect in the analyses of the duration of $\mathrm{V}_{1}(\mathrm{~F}(2,54)=10.9, \mathrm{p}<.001)$. Specific comparisons showed that the duration of $\mathrm{V}_{1}$ in the liaison context was longer than that of $\mathrm{V}_{1}$ in the illegal

3 Experiment 2 also provided an opportunity to address a problem remaining with the interpretation of Experiment 1. If the difference between the liaison and illegal liaison conditions were due to meaningfulness alone, then cross-splicing should have had no influence on the size of the effect. The effect of cross-splicing here therefore suggests that the legality effect is due to phonological factors rather than to semantic factors.

4 Four items had a preceding consonant instead of $\mathrm{V}_{1}$ in the enchainment condition (e.g., direct ancien). The acoustic measurements reported exclude these four items. 
liaison context $(\mathrm{F}(1,27)=14.4, \mathrm{p}<.001)$ but did not differ from that of $\mathrm{V}_{1}$ in the enchainment context $(\mathrm{F}(1,27)=2.0, \mathrm{~ns})$. There was also a significant context effect in the analyses of the duration of $\mathrm{C}(\mathrm{F}(2,54)=13.2, \underline{\mathrm{p}}<.001)$. Specific comparisons showed that the duration of $\mathrm{C}$ in the liaison context was shorter than that of $\mathrm{C}$ in the illegal liaison context $(\mathrm{F}(1,27)=25.6, \underline{\mathrm{p}}<.001)$ and shorter than that of $\mathrm{C}$ in the enchainment context $(\mathrm{F}(1,27)=4.2, \underline{\mathrm{p}}<.05)$. There was no context effect in the analyses of $\mathrm{V}_{2}(\mathrm{~F}(2,54)=1.97$, $\mathrm{ns})$.

In the legal liaison context, we observed lengthening of the vowel preceding the liaison consonant $(11 \%)$ and shortening of the liaison consonant $(15 \%)$ compared to the illegal liaison context. There are therefore acoustic-phonetic cues in the signal to differentiate initial consonants from liaison consonants. However it seems that the acoustic-phonetic variations associated to the liaison context are similar to those associated to the enchainment context. These variations are the lengthening of the vowel preceding the medial consonant and the shortening of the consonant itself in the two resyllabification contexts, relative to the illegal liaison context, where the speaker intended the medial consonant to be syllable initial (e.g., demi tagneau rather than demit agneau). Note, however, that the preceding vowel was not always the same vowel in the legal, illegal liaison and enchainment contexts. The analyses of the lengthening of the preceding vowel should therefore be interpreted with caution.

The pivotal consonant results are in line with the acoustic analyses of Spinelli et al. (in press). Measurements of twelve speakers' productions of ambiguous sentences with liaison showed that their pivotal consonants tended to be shorter (by between $10 \%$ and $18 \%$ of total consonant duration) for vowel-initial words (e.g., oignon in [sEl'dEÂnjeÂO^O\$]), than for consonant-initial words (e.g., rognon in [sEl'dEÂnjeÂO^O\$]).

\section{General Discussion}

Liaison involves the pronunciation of a word-final consonant which can be silent in other phonetic contexts. It therefore creates transient segmentation ambiguities. Hearing a $/ t /$ at the end of the word petit could mean either that the next word begins with a $/ t /$ or that it begins with a vowel. The present research examined how vowel-initial words are recognized in liaison contexts in French, given that such words undergo resyllabification, with an initial surfacing latent phoneme. This question was examined using a crossmodal identity priming paradigm. In Experiment 1, visual targets were recognized faster when the primes were presented in a context where liaison is legal (petit agneau) than in a context where a phoneme appears in a no-liaison environment (demi t agneau). In Experiment 2, we found that this effect was reduced when the tagneau's from petit agneau and demi $t$ agneau were cross-spliced. Finally, acoustic measurements revealed systematic durational differences between these two conditions both for the critical medial consonants and the preceding vowels.

\section{Lexical factors in the resolution of liaison}

It has been shown that vowel-initial candidates which in the context of liaison are misaligned with the beginning of the syllable and receive a latent phoneme as initial segment are as easy to recognize as vowel-initial candidates that do not undergo liaison (Gaskell et al., in press). Hence, despite the transient lexical ambiguities caused by the liaison situation, it seems that vowel-initial candidates do not suffer as a result of competition with consonant-initial candidates. In Experiment 1, we showed that listeners 
use their lexical knowledge to help resolve the segmentation problem caused by liaison. In the legal liaison condition (petit agneau), lexical context supports the attachment of the surfacing phoneme to the preceding word (the / $\mathrm{t} / \mathrm{can}$ be interpreted as belonging to petit), whereas in the illegal liaison condition (demi t agneau), lexical context does not allow the attachment of the /t/ to demi. In the latter case the consonant is likely to be interpreted first as belonging to the following word, since demi, unlike petit, does not have an underlying $/ t /$. The response times in the illegal liaison condition therefore reflect resolution of the competition between consonant- and vowel-initial candidates (including the target word, e.g., agneau). In legal liaison environments, however, these consonant-initial words are weaker candidates (since the liaison consonant can be attributed to the preceding word), so the vowel-initial word can be recognized more easily.

Our results are compatible with previous results of Dejean de la Batie and Bradley (1995). In their study, subjects were asked to detect the presence of word-initial $/ \mathrm{t} / \mathrm{as}$ in théâtre (theatre) in phrases like grand théâtre (big theatre, where grand has an underlying liaison $/ \mathrm{t} /$ ) and vrai théâtre (real theatre, where vrai does not have a liaison /t/). They found that subjects were slower in the potential liaison phrases (grand théatre) than in the noliaison phrases (vrai théâtre). Their results suggest that in the potential liaison condition, lexical hypotheses with initial vowels become activated and compete with the consonantinitial candidate (théâtre). Taken together, these results suggest that when a word that supports a final liaison consonant is encountered, the liaison consonant is interpreted as part of this word and vowel-initial candidates then become easier to recognize.

\section{Acoustic factors in the resolution of liaison}

We also demonstrated that acoustic factors play a role in disambiguating phrases with liaison. The reduced legality effect observed in Experiment 2 with cross-spliced stimuli suggests that when conflicting lexical and acoustic cues were present (i.e., acoustic cues in favor of an initial consonant in a lexical context licensing liaison, and vice versa), segmentation was impaired. As Spinelli et al. (in press) also argue, it thus seems that the acoustic cues associated with liaison are exploited in segmentation. Given that the stimuli were cross-spliced at the surfacing consonant, one relevant cue for liaison might be the nature of the surfacing (liaison) consonant itself. The resyllabified liaison consonants (e.g. $/ \mathrm{t} /$ in petit agneau) appeared to be $15 \%$ shorter on average than the syllable-initial consonants in the illegal liaison contexts (e.g. /t/ in demi tagneau). Note, however, that the legality effect was reduced but not reversed in the cross-spliced condition. This suggests that while durational cues (and perhaps other acoustic effects) in the critical consonants play a role in the resolution of liaison, they are not the only source of disambiguation.

\section{Implications for speech segmentation in French}

How could the recognition system exploit differences in consonant duration in the resolution of liaison? Spinelli et al. (in press) discuss three alternatives. The first would be to assume that the mental lexicon consists of detailed exemplars of words (Goldinger, 1998). If sufficient durational detail were stored in the mental lexicon, the duration of a consonant in the speech input could be matched directly with stored durations, and the better-matching lexical interpretation could be selected (e.g., a shorter/t/ would be a better match to petit than a longer /t/, making both petit and agneau easier to recognise). We disfavor this account since the fact that liaison consonants are shorter than word-initial consonants would have to be coded in the representations of every relevant word.

A second alternative account would involve distinct allophonic representations, namely syllable-initial and syllable-final consonants. If shorter consonants activated syllable-final 
allophones more strongly than longer consonants, words consistent with syllable-final allophones could in turn be more strongly activated (e.g., petit in the natural versus the cross-spliced version of petit agneau). Again, this would also help with the recognition of the vowel-initial word (agneau).

The third alternative is based on the PWC, which penalizes candidate words that are misaligned with likely word boundaries (Norris et al., 1997). As we described in the introduction, syllable boundaries provide alignment points in the segmentation of French. Liaison thus poses an apparent problem for the PWC account: How can listeners recognize agneau in petit agneau, where agneau appears to be misaligned with a syllable boundary before the final / $\mathrm{t} /$ of petit? We suggest that consonant duration acts to signal the location of the word boundary in liaison contexts. A relatively long consonant signals a word boundary before it (as in demi tagneau), making it hard to recognize the misaligned vowelinitial word (i.e, agneau suffers from the PWC penalty). But a relatively short liaison consonant (as in petit agneau) may signal a word boundary after it, such that the vowelinitial word is in fact not misaligned and can be recognized more easily.

While we cannot rule out the allophonic account, the PWC account provides a more unified description of lexical segmentation in continuous speech. There is now considerable evidence that listeners are sensitive to whether candidate words are aligned with likely word boundaries (see Cutler, McQueen, Norris \& Somejuan, 2001, for a recent review). The PWC account of word recognition in liaison contexts fits into this framework.

In summary, the results of this study show that when the lexical context signals a possible liaison, the segmentation of vowel-initial candidates is facilitated. Moreover, when the acoustic specification of liaison is weakened, the segmentation of vowel-initial candidates becomes more difficult. These results thus provide evidence for the role of both lexical and acoustic factors in the resolution of liaison in French.

Acknowledgements. Elsa Spinelli's research was made possible by fellowships from the Fyssen Foundation. We thank Juan Segui for his hospitality during testing. Part of this work was presented at the 41st annual meeting of the Psychonomic Society, New Orleans, November 2000.

\section{Elsa Spinelli}

Laboratoire de Psychologie Expérimentale

Université Pierre Mendes France

BP 47, 38040 Grenoble Cedex 9

elsa.spinelli@upmf-grenoble.fr

elsa.spinelli@psycho.univ-paris5.fr

\section{References}

Cutler, A., McQueen, J. M., Norris, D. \& Somejuan, A. (2001) : The roll of the silly ball. In E. Dupoux (ed.), Language, brain and cognitive development: Essays in honor of Jacques Mehler, Cambridge (Ma), MIT Press, 181-194.

Cutler, A. \& Norris, D. (1988) : The role of strong syllables in segmentation for lexical access. Journal of Experimental Psychology: Human Perception and Performance 14, 113-121.

Dejean de la Bâtie, B. (1993) : Word boundary ambiguity in spoken French. Unpublished dissertation. Monash University, Victoria, Australia.

Dejean de la Batie, B., \& Bradley, D. C. (1995) : Resolving word boundaries in spoken French native and nonnative strategies. Applied Psycholinguistics 16, 59-81. 
Dumay, N., Content, A. \& Frauenfelder, U. H. (1999) : Contribution de la structure syllabique de surface à la segmentation lexicale. Proceedings of the 2èmes Journées d'Etude Linguistiques (Nantes), 105-109.

Dumay, N., Frauenfelder, U. H. \& Content, A. (2002) : The role of the syllable in lexical segmentation in French: Word-spotting data. Brain and Language 81, 144-161.

Encrevé, P. (1988) : La liaison avec et sans enchaînement. Paris, Seuil.

Fougeron, C. (2001) : Articulatory properties of initial segments in several prosodic constituents in French. Journal of Phonetics 29, 109-135.

Gaskell, G., Spinelli, E. \& Meunier, F. (in press) : Perception of resyllabification in French. Memory \& Cognition.

Goldinger, S. D. (1998) : Echoes of echoes? An episodic theory of lexical access. Psychological Review 105, 251-279.

Imbs, P. (1971) : Trésor de la langue Française. Dictionnaire des Fréquences. Paris, Klincksieck.

McClelland, J. L. \& Elman, J. L. (1986) : The TRACE model of speech perception. Cognitive Psychology 18, 1-86.

Mehler, J., Dommergues, J., Frauenfelder, U., \& Segui, J. (1981) : The syllable's role in speech segmentation. Journal of Verbal Learning and Verbal Behavior 20, 298-305.

Nakatani L. H. \& Dukes, K. D. (1977) : Locus of segmental cues to word juncture. Journal of the Acoustical Society of America 62, 714-719.

Norris, D. (1994) : Shortlist: A connectionist model of continuous speech recognition. Cognition 52, 189-234.

Norris, D., McQueen, J. M., Cutler, A. \& Butterfield, S. (1997) : The possible-word constraint in the segmentation of continuous speech. Cognitive Psychology 34, 191-243.

Quené, H. (1992) : Durational cues for word segmentation in Dutch. Journal of Phonetics 20, 331350.

Segui, J., Dupoux, E., \& Mehler, J. (1990) : The role of the syllable in speech segmentation, phoneme identification, and lexical access. In G.T.M. Altmann (ed.), Cognitive models of speech processing, Cambridge (Ma), MIT Press, $263-280$.

Segui, J., Frauenfelder, U., \& Mehler, J. (1981) : Phoneme monitoring, syllable monitoring and lexical access. British Journal of Psychology 72, 471-477.

Spinelli, E., McQueen, J. M., \& Cutler, A. (in press) : Processing resyllabified words in French. Journal of Memory and Language.

Wauquier-Gravelines, S. (1994) : Segmentation lexicale en Français parlé. Proceedings of the XXèmes Journées d'Etude sur la Parole (Trégastel), 517-522.

Yersin-Besson, C. \& Grosjean, F. (1996) : L'effet de l'enchaînement sur la reconnaissance des mots dans la parole continue. L'Année Psychologique 96, 9-30. 